\title{
From Present Trans and Intersex(ed) Politics to Past Embodied Experiences
}

Riikka Taavetti

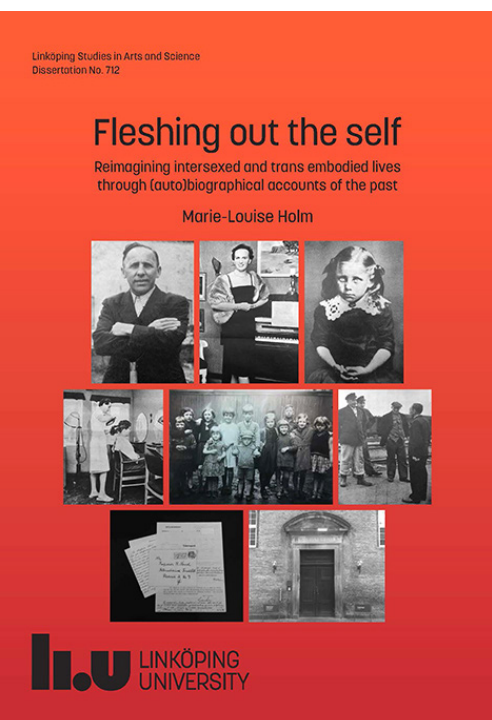

Marie-Louise Holm: Fleshing out the self: Reimagining intersexed and trans embodied lives through (auto) biographical accounts of the past. Linköping University, Department of Thematic Studies, The Department of Gender Studies. Linköping University, Faculty of Arts and Sciences. 2017. 426 pages.

http://liu.diva-portal.org/smash/ record.jsf?pid=diva2\%3A1095707 $\& d s w i d=4796$

Marie-Louise Holm's doctoral dissertation Fleshing out the self: Reimagining intersexed and trans embodied lives through (auto)biographical accounts of the past addresses the self-understandings of people who - in today's terminology - could be described as trans and intersex. The study focuses on Denmark between 1900 and 1970, a time before the medical categories of transsexualism and intersexuality became firmly established. Holm's thesis is a highly welcome contribution to the history of trans and intersex in the Nordic countries. As a well-grounded, thoroughly studied and engagingly written book, it is an important contribution also to queer history more broadly.

Holm's dissertation consists of three parts, the first being the introduction and the second discussing the theoretical aspects, methodology and position of the thesis in the fields of feminist activism and research as well as in the intersection of queer, trans and intersex studies. In the third part, Holm provides a contextualised analysis of two life stories by persons in trans or intersex(ed) positions who applied for the legal change of their gendersex status, as Holm innovatively names it. On the methodological level, Holm utilises dialogical narrative analysis by Arthur Frank and analyses the material discovered in the Danish National Archives, in case files for applications of legal sex change. In addition to the dialogical narrative approach, Holm calls their practice 'micro-genealogical' as they engage with detailed analysis of relatively few materials, although ones that are discovered by way of extensive archival research. The focus on Denmark is well motivated, as, in the present, the Nordic countries can boast of their tolerance and liberal politics. In particular, as Holm points out, Denmark plays a particularly important role in trans history, due to the internationally renowned case of Christine Jorgensen in the early 1950s.
Queer Eye

Reviews

Riikka Taavetti 
The genealogical approach connects Holm's study to the key theoretical questions in conducting queer historical research: how do we justify in contemporary research the perception of some past phenomena as predecessors of our current notions? In other words, particularly in Holm's analysis, how can we justify that the discussed cases are perceived as part of the history of trans and intersex? This discussion is complicated; indeed, it is often the case that the concepts used in the past, such as hermaphrodite or transsexual, may carry pejorative meanings in the present. In this study, it is rather obvious that the cases that Holm discusses have a relatively direct link to the eventually established definitions of transsexualism and intersexuality. It is always important to ask, however, what is left out when these aspects are studied and some others are omitted.

As Holm reads these individual stories into the history of trans and intersex, they take as a point of departure the medico-legal definitions that were applied to the individuals, not to the personal experiences. After all, it is only with these categorisations that Holm was able to discover the cases. This is by no means a shortcoming of the study, but an ambivalence that comes up in all queer historical research. One obvious way to avoid this would have been to not engage in the present-day discussions over trans and intersex, but that would have been an irresponsible choice, as it would have been left to the readers to realise how the topics studied are related to the issues of today. On the contrary, Holm's dissertation is very deeply - and from multiple perspectives - connected to present-day debates. Indeed, the extensive introduction and the methodological sections of the dissertation work as a thorough and critical discussion on the intersections between trans and feminist research.

Instead of focusing on the workings of medico-legal categories that defined trans and intersex(ed) individuals, Holm aims to acknowledge the diverse ways in which trans and intersexed individuals understood themselves.
This is an ambitious goal, and inevitably Holm quite often ends up describing and analysing how the medico-legal system understood these misfitting bodies. Indeed, on some occasions Holm could have analysed their material in more detail and perhaps gained deeper insights into the subjects' understanding of their experiences. For example, on page 270 when citing one of the main figures in the study, Vigga Heidi / Viggo Klausen, regarding their "joy and unspeakable happiness" after their legal sex change, Holm could have taken the opportunity to analyse what this happiness might have consisted in and what made it unspeakable.

All in all, Holm seems to achieve the goal of focusing on trans and intersex embodiment more effectively in the case of Peter Ole / Petra Oda Fischer than in that of Klausen. Whereas Klausen was working-class and, in today's terms, closer to what would be termed intersexed, Fischer, in turn, had a middle-class background and would in today's terms probably be called transgendered. According to Holm's analysis, Fischer's abilities to express themselves in writing and to engage with the contemporary medical understanding were much wider than those of Klausen. In addition, the gendered differences in the societal sanctioning of taking the role of a man vis-à-vis taking the role of a woman become evident. Indeed, it is only because of Holm's detailed analysis of the two cases that these structures become apparent.

While the length of the introductory section results in multiple definitions of what the thesis is actually about, it also gives Holm space to do careful and detailed work in analysing the central concepts of the study. Holm is exceptionally considerate in their choice of words and achieves conceptual innovation in the dissertation. For example, one concept that Holm introduces in the thesis, gendersex, is an elegant way to work one's way out of the binary formed by the sex/gender distinction. Especially for trans studies, Holm provides detailed and well-argued discussions, such as on 
the concept of passing (unfortunately hidden in the footnote on p. 294). Likewise, in my opinion, the question of which personal pronouns to use when referring to people who may not in all points of their lives fully fit into the binary system is solved in a highly nuanced manner and reflects the complexity of the issue. Unlike Holm assumes, however, this choice was not at all irritating, at least not for me as a reader; on the contrary, I found it enlightening as it rendered visible the gendered choices throughout the text.

Holm's work offers essential insights for queer historical research, even though this is not the primary field in which they place their study. Queer history has often defined its subject as one at odds with the normal (e.g. Halperin 2002, 62). But Holm states that many of those they study were not able to identify as anything other than "normal," in this context, as heterosexual men and women (p. 105). Holm does not engage much with the queer historical discussion, which, on some occasions, could have helped to further elucidate the analysis. For example, when Holm describes how the prevention of homosexuality was central to the medicolegal system, the study could have addressed just a bit more the Danish or Nordic studies on the history of homosexuality. As it stands now, the assumption that same-sex relationships were a taboo (p.220) is left without a proper contextualisation.

Holm begins their discussion of the two core cases by re-writing their autobiographies in first-person narration. While I find this re-articulation of the autobiographies a powerful and affective choice, I would have welcomed a short discussion on the possible problems it also raises. The material employed for this reconstruction is, after all, text produced under a very specific system of legal-medical control of misfitting bodies. What happens when these narratives are combined by a researcher into a coherent, first-person narrated life story? Is there not a danger of accepting the autobiographical narration as a transparent lens on the writer's life and thereby losing the insights offered by perceiving it as a construction by the researcher in the present? Nevertheless, later in their analysis Holm does carefully dissect these life stories.

On the level of style, Holm's dissertation is well-written and extremely engaging to read. It is also courageous in its experimentation with different forms of academic writing. The only choice that I found problematic is the extensive use of footnotes in some sections of the study. Relying heavily on footnotes is not only a question of style, but footnotes can also create a double narrative that might no longer support the clarity of the argument. In addition, at least from the perspective of a Nordic reader, it would have been useful to have the original Danish texts available when the translations are done by the author. For example, it is sometimes unclear how the personal pronouns that Holm is so careful with, are used in the original.

As a whole, Marie-Louise Holm's dissertation is an important contribution to queer history in general, and in particular to Nordic trans and intersexed history. Towards the end of their work, Holm raises an important ethical point when they emphasise the importance of acquiring more public and rearticulated life stories of trans and intersex people. This is one of the many contributions that this work offers. Holm's work powerfully questions the idea that a "liveable life" could only be the one that is unambiguously gendered and shows the possibilities of changing gender positions during one's life course. And finally, as a great study does, Holm's dissertation offers plenty of food for thought and ideas for what could be studied in the future.

\section{References}

Halperin, David M. 1995. Saint Foucault. Towards a Gay Hagiography. New York: Oxford University Press.

$$
\text { . }
$$

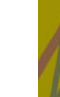

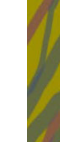

